Área Abierta. Revista de comunicación

audiovisual y publicitaria

ISSN: 2530-7592 / ISSNe: 1578-8293

https://dx.doi.org/10.5209/arab.78212

\title{
Imagen animada, jingle y sincronía: una combinación audiovisual para el recuerdo publicitario televisivo de los años sesenta
}

\author{
Rafael Ángel Rodríguez López ${ }^{1}$
}

Recibido: 1 de octubre de 2021 / Aceptado: 3 de diciembre de 2021

Resumen. La publicidad comercial de los años sesenta encontró con la irrupción de la televisión en España el mejor medio para la promoción de marcas: a través del uso síncrono entre la imagen animada y un tema musical cantado, el jingle. Partiendo de esta premisa, a través de una metodología de análisis audiovisual aplicado a dos spots publicitarios pertenecientes a los Estudios Moro de publicidad española, el principal objetivo de este artículo es demostrar cómo el uso de ambos elementos visuales y sonoros fueron determinantes para que el público obje tivo recordará con facilidad el producto que estaba siendo promocionado en televisión.

Palabras clave: publicidad; televisión; anuncios; animación; Jingle

\section{[en] Animated Image, Jingle and Synchrony: An Audiovisual Combination for the Television Advertising Memory of the Sixties}

\begin{abstract}
Commercial advertising in the 1960s found with the irruption of television in Spain the best medium for the promotion of brands: through the synchronous use of the animated image and a sung musical theme, the jingle. Starting from this premise, through a methodology of audiovisual analysis applied to two advertising spots belonging to the Moro Studios of Spanish advertising, the main objective of this article is to demonstrate how the use of both visual and sound elements were decisive for the target audience to easily remember the product that was being promoted on television. Keywords: advertising; television; commercials; animation; Jingle
\end{abstract}

Sumario. 1. A modo de introducción. 2. Marco teórico y metodología. 3. Los años sesenta: el florecimiento de un nuevo medio para la publicidad. 4. La animación: imagen protagonista en la publicidad de los sesenta. 5. Jingle y sincronía: recursos para el consumo publicitario. 6. Análisis audiovisual: exposición de los resultados. 7. Para concluir. 8. Bibliografía.

Cómo citar: Rodríguez López, R. Á. (2022). Imagen animada, jingle y sincronía: una combinación audiovisual para el recuerdo publicitario televisivo de los años sesenta. Área Abierta. Revista de comunicación audiovisual y publicitaria 22 (1), 31-45, https://dx.doi.org/10.5209/arab.78212

\section{A modo de introducción}

La imagen animada, junto con la fusión de música y letra -el jingle - y la perfecta sincronía entre ambos elementos audiovisuales es, desde el nacimiento de la televi-

1 Universidad de Córdoba (España).

E-mail: z52rolo@uco.es

ORCID: https://orcid.org/0000-0002-1112-2762 
sión, uno de los principales recursos publicitarios para persuadir al público objetivo e inducirlo al consumo del producto que está siendo promocionado. Esta dualidad visual y sonora, que floreció en España a finales de los años cincuenta con el propósito, como decimos, de potenciar en el target $^{2}$ un deseo consumista, ha sobrevivido a una sociedad española en evolución desde el comienzo de los años cuarenta.

La llegada de la televisión supone un auténtico revulsivo por cuanto se refiere a una nueva forma de hacer publicidad que, hasta entonces, era un privilegio concedido a la cinematografía con las proyecciones de películas publicitarias de corta duración, cuyo formato se podría considerar como el antecesor de los anuncios televisivos y de otras composiciones publicitarias para la promoción de marcas o productos como los carteles, las vallas, la prensa o la radio. En este pretexto, tal y como señala Montero, "la publicidad hizo posible el desarrollo de la televisión en España. Gracias a ella, también el país pudo evolucionar hacia el progreso económico más potente hasta entonces conocido" (2014: 139). De esta forma, durante los años sesenta, se produce un aumento considerable en la emisión de anuncios publicitarios -alimentación, bebidas, electrodomésticos, medicinas- que comienzan a copar la programación televisiva y cuyo interés hacia esta nueva forma de publicidad es despertado mediante el movimiento de una imagen animada en sincronía con un recurso de vital importancia para la radio, el jingle.

En este sentido, dado el valor persuasivo de este binomio al que nos hemos referido con anterioridad, el presente artículo tiene como objetivos, por un lado, comprobar qué parámetros audiovisuales son comunes durante el desarrollo de la secuencia publicitaria y, por otro, analizar el comportamiento síncrono entre la imagen animada y el jingle como recurso para favorecer el recuerdo publicitario del producto en el espectador. Por consiguiente, es nuestra intención en las líneas que siguen, desmenuzar la simbiosis entre ambos elementos audiovisuales, imagen y música jingle-, que durante el primer periodo de la publicidad española (1955-1970) sirven para atraer al target y cuya representación se encuentra ahora, como decimos, en la pequeña pantalla. Una dualidad visual y sonora que ha perdurado hasta el actual panorama publicitario español.

En torno a ello, nos introducimos, a continuación, en el análisis audiovisual de dos spots televisivos que hemos tomado como propuestas publicitarias, tales como el creado para el bicarbonato Torres Muñoz y el realizado para la bebida Fundador, ambos realizados por los Estudios Moro de publicidad española, y que reflejan, de algún modo, la importancia de la imagen animada junto con el jingle para el recuerdo imborrable del producto en el tiempo. ${ }^{3}$

\section{Marco teórico y metodología}

\subsection{Marco teórico}

A la hora de plantear esta investigación, nos apoyamos, en primera instancia, en el marco social, político, económico y cultural en el que se desarrolla el nacimiento

\footnotetext{
Palabra que se utiliza en el sector publicitario para referirse al público objetivo.

Queremos resaltar que, durante el desarrollo de esta investigación, los anuncios analizados pertenecen a los Estudios Moro de publicidad que, como argumenta Fernández, "obtuvieron casi la exclusividad publicitaria que los 1levó a realizar el 90\% de la publicidad de Televisión Española durante los años sesenta” (2007: 91).
} 
de la televisión en España de la mano de Palacio (2008), Rueda Laffond junto a Chicharro (2006), y Bustamante (2013). En segundo lugar, en referencia al contexto histórico que abarca la década de los sesenta, en relación con la nueva forma de comunicación social que resulta ser el mecanismo ideal para el consumo o compra de un producto, la publicidad comercial, los textos de Eguizábal (1998) y Montero (2011 y 2014), establecen unos cimientos teóricos para construir un contexto y marcar unos límites historiográficos sobre los que asentar este estudio. ${ }^{4}$

En lo relativo a cuestiones formales sobre la creación de la secuencia visual compuesta de varios fotogramas realizados en dos dimensiones, comúnmente conocida como la imagen animada, son de especial interés las obras propuestas por Candel (1993) y Fernández (2007), por cuanto nos permiten conocer la aplicación publicitaria de esta disciplina artística en los diferentes formatos audiovisuales, tales como el cine y la televisión. Los citados autores, a su vez, suponen una fuente importante de anuncios publicitarios creados en exclusividad por los Estudios Moro de publicidad española durante su primera etapa televisiva. De manera que nos dan acceso a la selección, entre una amplia recopilación de anuncios, de aquellos que mejor se adaptan al objeto de estudio que, recordemos, se basa en la idea del empleo síncrono entre imagen y música para el recuerdo publicitario. Asimismo, en cuanto al marco de la utilización del jingle como parte del mensaje publicitario y las funciones comunicativas de la música en un contexto más general, son esenciales las obras de Guijarro (2007) y Darias de las Heras (2018), puesto que se pueden trasladar una serie de conceptos, aplicados sobre todo a este tipo de música original para publicidad, a esta investigación.

\subsection{Metodología}

Una vez establecida la base teórica y formal sobre aquellas características que representan la imagen animada y el jingle, asignaremos dichos conceptos a una metodología de análisis audiovisual conjugada por autores como Gómez Rodríguez (2005) y Sánchez Rodríguez (2015). Por consiguiente, con el fin de mostrar una mejor exposición de los rasgos que componen la secuencia de los anuncios publicitarios, se procede a seleccionar los siguientes parámetros audiovisuales que quedan representados en el cuadro que se muestra a continuación -Tabla 1-:

\begin{tabular}{|c|}
\hline Fotograma y acompañamiento musical jingle \\
\hline Procedencia de la música \\
\hline Imagen \\
\hline Duración \\
\hline Sincronía utilizada \\
\hline
\end{tabular}

Tabla 1. Parámetros audiovisuales analizados en los anuncios publicitarios.

[Fuente: elaboración propia]

4 Debemos señalar que durante el desarrollo de esta investigación, siempre que se hable de publicidad, se hará en referencia a la conocida como comercial, no refiriéndose en ningún caso a la conocida como publicidad institucional que, tal y como define Módenes, es "un tipo de comunicación que en su mayoría procede del Estado y que, a diferencia de la publicidad comercial o de la propaganda, no tienen entre sus objetivos prioritarios ni la venta de productos ni la difusión de una determinada ideología política" (2017: 14). 
Para su desarrollo, nos apoyaremos en algunas nomenclaturas derivadas de autores como Román (2017) y Chion (1993; 2017), a saber, la procedencia de la música, siendo necesario distinguir entre aquella cuyo foco sonoro se puede visualizar en la secuencia -diegética-o, por el contrario, aquella que no tiene su representación en pantalla, los personajes no pueden escucharla y, por consiguiente, no pertenece a la narración de la historia - extradiegética-, así como el uso de los distintos tipos de sincronía que pueden ser utilizados para la imagen audiovisual. ${ }^{5}$

De esta forma, durante el desglose visual y sonoro atenderemos, en primera instancia, a la captura del fotograma para conocer de forma precisa cuál es el acompañamiento musical que le sigue. Así, lograremos ver qué sílabas, palabras o frases, que componen el jingle publicitario, apoyan el movimiento de la imagen animada en representación al producto promocionado. Acto seguido, será necesario observar la diégesis de la música para conocer su procedencia. Al mismo tiempo, se establecerá si el spot está compuesto por una imagen tan solo animada o contiene algunas fotografías reales durante el desarrollo del anuncio $\mathrm{y}$, además, veremos la duración de cada spot con el objetivo construir una comparativa entre ambos y observar si utilizan una duración similar en el metraje para promocionar un producto en televisión.

Por último, analizaremos en este estudio uno de los parámetros más importantes para activar el recuerdo de la marca gracias a su alto poder comunicativo. Hablamos aquí del grado de sincronía -eventual o dura-, que tiene lugar entre la imagen y la música. En este sentido, cuando nos referimos a un grado de sincronía eventual, tal y como señala Román, se trata de aquella sincronía en la que "solo algunos puntos de la secuencia están enlazados con la música" (2017: 156); a su vez, prosigue Román, en referencia a la sincronía dura, es aquella "donde la sincronía es tan presente y marcada que puede considerarse mickeymousing" (2017: 156).

Cabe resaltar que a lo largo del artículo se establecerán dos ejemplos comparativos que refuerzan o contrastan las características establecidas en relación con la imagen y la música aplicadas a los diferentes spots publicitarios. De forma que ofreceremos distintos modelos que nos sirvan para sostener esta investigación.

\section{Los años sesenta: el florecimiento de un nuevo medio para la publicidad}

Tal y como señala Rueda Laffond y Chicharro:

La década de los sesenta constituyó un verdadero punto de inflexión para el sector publicitario español: en este marco, el medio televisivo ejerció como una herramienta de primer orden en la expansión de la promoción comercial. Además, al igual que la propia publicidad, la televisión actúa como espejo y dinamizador en la popularización de nuevos hábitos y actitudes, ligados a las prácticas de la cultura de consumo masivo. (2006: 26)

\footnotetext{
Aunque los parámetros audiovisuales que emplean los citados autores están más orientados al análisis de la imagen y música cinematográfica, queremos señalar que son destinados a este estudio publicitario por su perfecta adaptación respecto a los aspectos visuales y sonoros de las secuencias y planos televisivos.
} 
Conocida como la década prodigiosa -así se les llama de manera habitual a los años sesenta- nos encontramos en un periodo lleno de cambios y contrastes en las que "palabras como desarrollismo, tecnócratas, rentabilidades, eficacia, consumismo se integran con fuerza en el vocabulario de los españoles" (Palacios Bañuelos, 2020: 12). Y es que, en estos años, España sufre una importante transformación a nivel político, económico, social y cultural. Así, se produce el abandono del periodo autárquico del Régimen instaurado en 1943: la España que es conocida como rural ahora pasa a ser industrial; el Turismo incide con fuerza en la economía; se aprueba la Ley de Prensa e Imprenta que "promete" la libertad de expresión escrita, suprimiendo de esta manera la censura previa; la publicidad experimenta un auge; la televisión se convierte en el medio más utilizado - en detrimento de la radio o el cine- y los spots publicitarios hacen su puesta en escena para el consumo masivo de productos. De esta forma, "un crecimiento económico sin parangón, una avidez consumista como nunca se había conocido, el desarrollo de las técnicas del marketing, la televisión, el aumento de tarifas publicitarias, etc., hicieron de esta década una nueva era de oro publicitaria" (Eguizábal, 1998: 374).

De entre todos los sucesos que se enmarcan en estos años, la llegada de la pequeña pantalla, un 12 de octubre de 1956, supone un impacto social enorme en la década que está por llegar, los sesenta-imagen 1-, y aunque las primeras programaciones de este medio audiovisual tienen que ver más con sucesos políticos del Régimen, tales como "la retrasmisión en abril de 1959 del traslado de los restos de José Antonio Primo de Rivera o la información sobre la visita del presidente Eisenhower a Madrid" (Bustamante, 2013: 42), la emisión de anuncios publicitarios para la promoción de productos se introduce de forma radical en la programación de los españoles. ${ }^{6}$

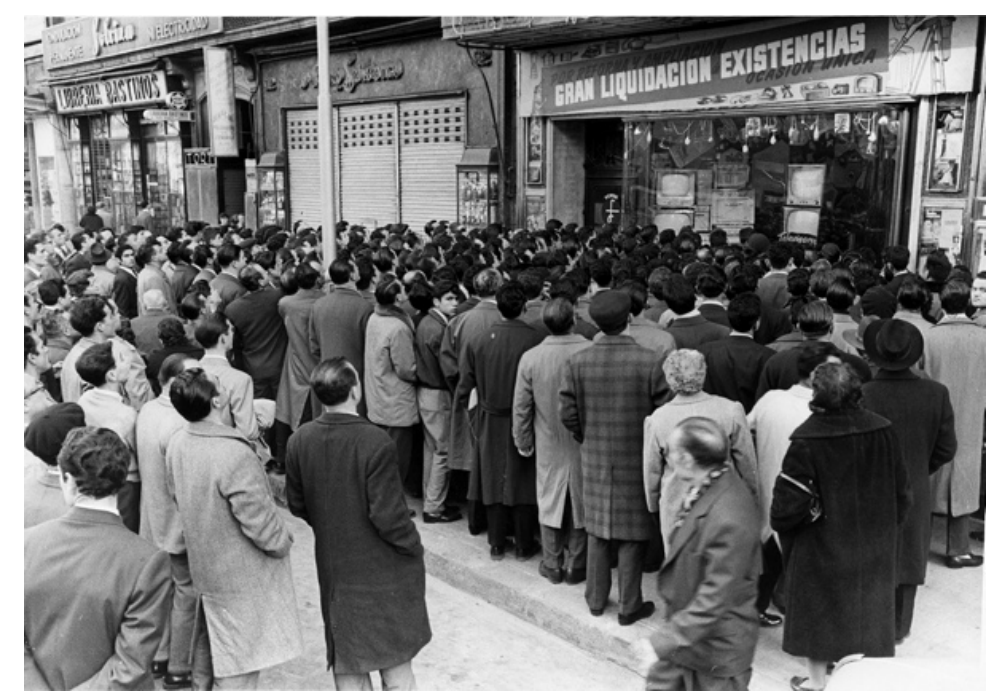

Imagen 1. Ciudadanos españoles aglutinados para ver la televisión.

[Fuente: Hemeroteca/ La vanguardia]

Pese a que la televisión no llega a los hogares españoles hasta los años cincuenta, tal y como recoge Martín en su artículo bajo el título "Aproximación a la historia y al papel de la televisión en la emigración española a Europa", "el primer televisor llegó a España durante la guerra civil, cuando Adolf Hitler regaló al caudillo un Telefunken, en 1938" (2014: 62). 
En todo este proceso de cambio en el que se encuentra inmersa la población española, el nuevo medio tiene un papel esencial, casi protagónico, que genera un modelo de sociedad consumista. En base a ello, Montero argumenta que "el consumo español fue altamente cuantitativo, casi voraz, sobre todo acrítico. A veces la mera posesión de algo, con independencia de su calidad y precio, era un importante signo de estatus, por ejemplo, el aparato de televisión" (2011: 264). Así, se traduce de forma repentina en un fenómeno de masas. Su aparición, además, aporta la creación e implantación de agencias publicitarias nacionales y extranjeras, y cientos de anunciantes ${ }^{7}$ quieren mostrar ahora sus productos a través de espacios publicitarios, cuyos mensajes, en forma de imagen y música, son retenidos en nuestra memoria con una facilidad asombrosa. ${ }^{8}$

Hasta el momento, "la primera publicidad audiovisual había llegado de la mano del cine [...] Estamos en una época -en los años cincuenta- en la que existían más de siete mil cines, con una asistencia anual superior a los cuatrocientos millones de espectadores" (Bustamante, 2006: 18). Precisamente, la publicidad visual y sonora se encuentra en el ámbito cinematográfico, que, como argumenta Galán, "se desarrolló prioritariamente a partir de pequeñas historias realizadas expresamente para dar a conocer una marca o producto" (2010: 96). Prosigue así Galán:

Estos anuncios podían tener, como es lógico, distinta facturación y duración. Las obras realizadas expresamente para un anunciante, generalmente de una duración superior a un minuto, reciben el nombre de películas publicitarias, y a veces incorporaban, incluso, una cabecera de títulos de crédito específicos. Por otro lado, si el anuncio era de treinta segundos, se le denominaba filmlet. En ese caso las historias no siempre eran originales, y el anunciante podía ahorrarse una buena cantidad de dinero optante por utilizar imágenes e historias diseñadas para otras creatividades. Años más tarde esta fórmula se convirtió en un género específico y recibió el nombre de prefabricado. El prefabricado duraba solo quince segundos, y siempre estaba compuesto por imágenes filmadas que el anunciante elegía de un catálogo. A dichas imágenes se les añadían unas colas con el nombre del producto y de ahí se pasaba directamente al circuito de exhibición. (2010: 87)

No obstante, la irrupción de la pequeña pantalla en España supone el declive, como decimos, del medio cinematográfico y radiofónico. La implantación y el avance del nuevo medio de comunicación se convierte para la publicidad comercial de los años sesenta en un edén, dado que las marcas publicitarias pueden promocionar sus productos en un espacio breve de tiempo y llegar a cientos de hogares españoles. ${ }^{9}$ Como señala Palacio, "la televisión parece satisfacer una mayúscula demanda

7 Del latín, annunciare. Empresa o instituciones que contratan a las agencias publicitarias para la compra y desarrollo de espacios publicitarios.

8 Para conocer más sobre la implantación de las agencias publicitarias -nacionales y extranjeras-en la España de la década de los sesenta, véase el artículo de Bravo (2000), referente a la incorporación de las multinacionales al panorama publicitario español.

9 Para tener una idea del crecimiento del número de televisores que llegaban a los hogares españoles en los años sesenta, tal y como señala Palacio, "según TVE, creció: 1963, 850.000 televisores, 1964, 1.1000.000; 1965 , 1.425.000; 1966, 2.125.000; 1969, 3.897.000” (2008: 58). A su vez, para complementar esta información, véase el informe que emitió FOESSA en 1966. 
de ocio cuasi gratuito y doméstico no cubierta por otras formas de entretenimiento social" (2008:54). Ahora, la combinación de imagen, sonido, color -en algunos casos-, movimiento, dibujos animados y jingles, cuyas melodías provocan el recuerdo instantáneo del producto, hacen de la televisión el soporte ideal para la publicidad comercial. Por consiguiente, los creadores de anuncios publicitarios tienen que acostumbrarse a pensar en imágenes en movimiento acompañadas de una melodía cantada para crear una huella sonora imborrable en el tiempo.

\section{La animación: imagen protagonista en la publicidad de los sesenta}

Como señalan Jiménez, Lavín y Gómez, citando las palabras de Candel (1993), "el origen de la animación española comienza en la segunda década del siglo xx, de manos de Segundo de Chomón, con unas producciones basadas en trucos, muñecos y diversos dibujos donde el cine era considerado todavía una atracción de feria" (2019: 38). Continúan los citados autores argumentando que, "debido a su carácter experimental, las animaciones estaban dirigidas a un público adulto y eran realizadas de forma autodidacta" (2019: 38). Y es que, antes de llegar la animación a la televisión como forma publicitaria para el consumo, este tipo de imagen tuvo sus inicios en la gran pantalla, donde el dibujo animado permitía una mayor creatividad y dotaba al spot de un poder persuasivo absoluto.

Sin embargo, en términos televisivos, para hablar de la animación publicitaria hay que remontarse hasta la década de los sesenta, una época donde se reproducen cientos de películas, se conceden los primeros premios y, como menciona Jiménez, Lavín y Gómez, es una etapa "dominada por un estilo Disneyano que marcó escuela en los Estudios Moro" (2019: 38). Por tanto, para referirnos a la imagen animada para publicidad es imperativo mencionar a los responsables en crear un modelo publicitario que combina el dibujo animado -a veces junto con la imagen real-y la música de forma extraordinaria y cuyos anuncios perduran en nuestra memoria colectiva hasta hoy; los realizados por los hermanos Santiago y José Luis Moro, a los que Fernández se refiere de esta forma -Imágenes 2 y 3 -

La labor creativa de los Estudios Moro forma parte de la historia de la publicidad española, no solo por ser los pioneros de la publicidad de animación en España, además de grandes creativos. En ella ocupa un lugar de excepción tanto por su calidad, ingenio, modernidad, reconocimientos internacionales y premios logrados, cuanto por su capacidad artística y emotiva para marcar nostálgicamente los llamados años del bum económico y el desarrollo industrial de las España de los años cincuenta y sesenta. Hay que resaltar el trabajo de animación realizado por los Estudios Moro y la cantera de dibujantes españoles que se iniciaron con ellos y luego se independizaron. A este periodo, comprendido entre el 1955 y 1970, se le considera historiográficamente como la segunda era de oro de la animación española. (2007: 60)

Así pues, durante esta década se produce lo que se conoce como la segunda era dorada del dibujo animado español, ya que la mayor parte de los anuncios creados durante este periodo están elaborados con técnicas de animación: "de cada diez anuncios realizados por los Estudios Moro, cinco eran de animación, dos de animación de objetos y tres de imagen real" (Fernández, 2007: 137). Todos los productos publicitados en televisión tuvieron su representación animada. Su simplicidad, naturalidad, picaresca y sentido del humor son las razones por las que se emplea la 
animación para la venta de un producto. De estas características, que hacen más fácil la fluidez comunicativa con el público objetivo, emanan cientos de spots -animadostelevisivos en las que la narración publicitaria gira entorno a una historia, un slogan y un tema musical - con letra- pegadizo que quedaba guardado en la memoria de aquellos que los veían.

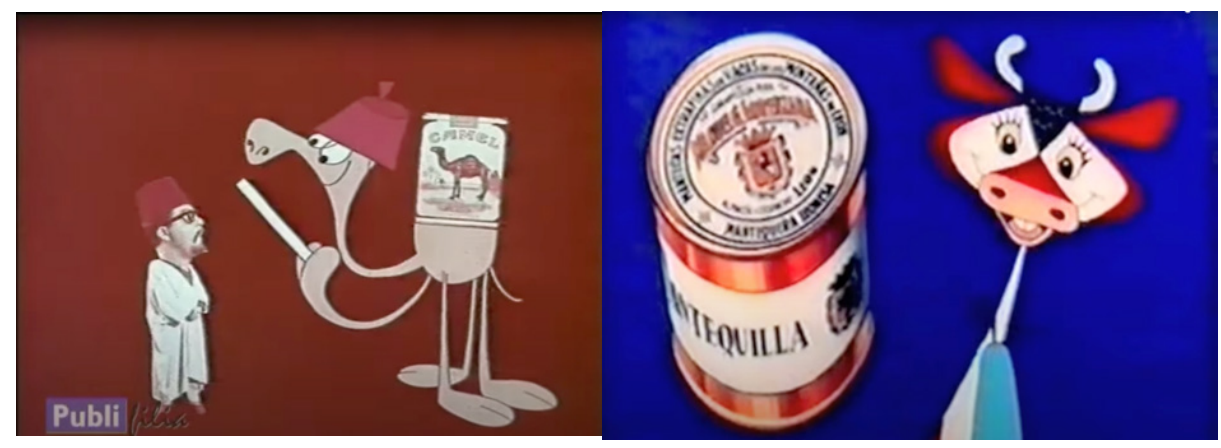

Imágenes 2 y 3. Mustafá para Cigarrillos Camel (izquierda) y La Vaca Marcelina para Mantequilla Lorenzana (derecha). De los Estudios Moro para Movierecord S.A.

[Fuente: El anuncio de la modernidad]

\section{Jingle y sincronía: recursos para el consumo publicitario}

Cuando no tenga nada que decir, cántelo.- Ogilvy ${ }^{10}$

Tal y como señala Bassat:

La música sirve para comunicar cosas que no se pueden comunicar mejor de otra manera: una sensación, un estilo, una clase, un estado de ánimo, etc. Por eso, no sirve cualquier música para cada producto, para cada circunstancia. La selección del tipo de música requiere tanto tiempo como la selección del tipo de imagen que queremos para el producto. (1993: 157)

Que la publicidad televisiva de estos primeros quince años del nacimiento del nuevo medio audiovisual en España eligiese al jingle como instrumento persuasivo más utilizado para acompañar a la animación y, como consecuencia, activar el recuerdo instantáneo del público objetivo, no era una simple casualidad. Es necesario resaltar que este tipo de música original fue -y es, en el panorama actual publicitariouno de los recursos sonoros más empleados por el medio de comunicación anterior a la televisión, la radio, dado que, gracias a él, podían ser reconocidas las emisoras y los anunciantes que en ellas se reproducen con solo escuchar una breve melodía con letra. Sobre ello, Darias expone que "con la llegada de la radio comercial, el jingle pronto se convertiría en una herramienta puramente musical, en un arte en sí mismo

10 Está es la frase con la que David Ogilvy hace referencia a la música publicitaria (Bassat, 1993: 156). 
mucho antes de que se probara científicamente que las melodías se quedan insertadas en nuestro cerebro durante mucho más tiempo que las simples palabras" (2018: 137).

En este sentido, la razón que sustenta el uso - excesivo en ocasiones-de este tipo de música original, que fusiona música y letra, se fundamenta por ser un elemento capaz de proyectar la imagen del producto promocionado en el receptor en cuestión de segundos. Como argumenta Guijarro, "en publicidad, el producto ligado a una canción, si se ha realizado de forma efectiva, puede perdurar en el tiempo indefinidamente" (2003: 104). Del mismo modo, Segarra señala que "una frase, una musiquita, una idea, un anuncio en sí mismo, se convierte y forma parte de la cultura popular, pasa a ser propiedad de la gente y creemos que al final ese es un poco el cielo de los anuncios. Que la gente lo recuerde como parte de su vida" (Los Oficios de la Cultura, RTVE, 2011). Por consiguiente, como hemos citado antes, la unión de música y letra contiene un alto índice recordatorio y reconocimiento de la marca/producto. Aquí, la música ayuda a proyectar y retener la imagen del producto en sí mismo en nuestra memoria.

Prosigue en esta misma línea Darias:

La música ya se utilizaba mucho antes en ventas callejeras para incitar la compra de productos o, cuanto menos, para que el público recordara el mensaje publicitario. El jingle, existía ya desde el siglo XVII en una versión más en forma de rima que cantada y fue recuperado en la publicidad de EE. UU. en el siglo XIX como complemento al slogan, herramienta habitual desde mitad de ese siglo. Así, los jingles previos a la radio eran rimas que aparecían en la publicidad de los tranvías. Uno de los pioneros fue el de la compañía De Long Hook and Eye. Curiosamente, algunos jingles se volvieron tan populares que fueron adaptados a canciones del momento, como el del crecepelo Newbro's Herpicide, cuyos fans cantaban utilizando la melodía de la canción "Harrigan, That's Me". (2018: 136)

En un breve periodo de tiempo, por lo general sin superar los treinta segundos de duración, ${ }^{11}$ el jingle contiene en sí mismo una gran variedad de elementos sonoros, formales y lingüísticos que, junto con las diferentes características de la imagen animada, son el principal recurso para captar la atención del target, obtener un recuerdo duradero y, por tanto, aumentar el beneficio en el consumo del mismo. En este mismo sentido, Darias, citando las palabras de Mireille Besson y Daniele Schön, señala al respecto que "tanto música como el lenguaje se basan en sistemas con elementos básicos -fonemas, palabras, notas y acordes- que se combinan en estructuras de orden más elevado, frases musicales, lingüísticas o temáticas" (2018: 60).

Pues bien, el jingle se convierte en un recurso fundamental para aportar la notoriedad necesaria y destacar las partes más importantes de la secuencia audiovisual a la que acompañan. Es decir, de la composición de este tipo de música original, que no deja de ser sino un lenguaje musical en sí mismo, se espera que una palabra sea acompañada en un momento determinado de la composición audiovisual por una

11 Durante esta primera etapa de la publicidad española, otros anuncios publicitarios utilizaban este estándar en la duración para promocionar sus productos. Lo podemos encontrar en anuncios publicitarios como SuperKOKI, Yo sí como patatas, Aceites Ybarra o los spots creados para las bebidas alcohólicas, como coñac Espléndido y la ginebra Fockink, entre otros muchos. 
nota o acorde musical. Es aquí donde entra en juego el grado de sincronización realizado entre ambos elementos audiovisuales.

Cuando hablamos de sincronía"12, como bien expone Chion, nos referimos "a un recurso de soldadura irresistible y espontánea que se produce entre un fenómeno sonoro y un fenómeno visual momentáneo cuando estos coinciden en un mismo momento, independiente de toda lógica racional" (1993: 75). Por ello, si esta expectativa se cumple, el espectador no perderá la atención de la pantalla, la persuasión será mucho mayor y, por lo tanto, se traducirá en una hipotética compra/consumo del producto. En caso contrario, el no enlazar lo que se ve con lo que se escucha, provoca que el receptor tienda a desvincular su atención de la pantalla. De ahí, la importancia de la sincronía. Asimismo, Sedeño señala que "mediante la sincronía y los puntos de sincronización se puede crear una gran cantidad de efectos narrativos y expresivos, así como conducir la atención visual hacia un hecho que coincide con el sonido que se escucha" (2008: 130).

Con todo ello, nos sumergimos a continuación en el estudio de los anuncios publicitarios citados de forma previa para observar cómo el empleo síncrono de la imagen animada y la música -jingle- se ha utilizado desde los inicios publicitarios en España para provocar el recuerdo del producto de forma instantánea.

\section{Análisis audiovisual: exposición de los resultados}

El presente apartado es el resultado de este estudio cuyo contenido comprende el análisis audiovisual de dos spots publicitarios, bicarbonato Torres Muñoz y coñac Fundador, enmarcados, como se comentó con anterioridad, en el primer periodo de la publicidad española y que representan, de la mejor manera posible, las características audiovisuales mencionadas en el artículo. ${ }^{13}$ Precisamente, con el análisis de los anuncios de esta etapa, se pretende obtener una visión global de aquellas características del metraje que solían ser utilizadas para la promoción del producto en televisión y que, como se desarrolla a continuación, presentan una serie de parámetros comunes a todos ellos.

Pues bien, si nos adentramos ahora en los ejemplos que se proponen para este artículo, uno de los anuncios que marca un estándar audiovisual en referencia a la composición del spot publicitario para la televisión en España se encuentra con el realizado para el bicarbonato Torres Muñoz -Tabla 2-. ${ }^{14}$ El producto que lleva por nombre el apellido del farmacéutico Guillermo Torres Muñoz alcanzó la fama publi-

12 Chion define la sincronía como "un punto de sincronización, en una cadena audiovisual, es un momento sobresaliente de encuentro síncrono entre un momento sonoro y uno visual: un punto en que el efecto de síncresis -palabra que combina sincronismo y síntesis- es más acentuado, como en música un acorde más afirmado y reforzado que otros" (2017: 76).

13 Ante la enorme variedad de anuncios publicitarios emitidos en televisión durante estas casi dos décadas, se ha procedido a realizar, como decimos, una selección de aquellos que mejor representan todo lo expuesto anteriormente. Asimismo, cabe señalar que el estudio de los citados espacios audiovisuales en televisión se ha realizado sin tener documentación musical tangible. Sin embargo, gracias al ritmo musical, letra de los jingles y poder constatar el comportamiento en tiempo real de la frecuencia sonora junta con la imagen de cada spot, se ha logrado establecer un análisis audiovisual con garantías.

14 Véase: bicarbonato Torres Muñoz [video]. YouTube. https://www.youtube.com/watch?v=e7MwCgNjj_8

(Fecha de acceso: 14/07/2021). 
citaria televisiva con un anuncio repleto de carisma, simpatía y acompañado de un jingle que, una vez escuchado, es difícil de olvidar. ${ }^{15}$

\begin{tabular}{|c|c|c|c|}
\hline FPS $^{1} .1$ & FPS. 2 & FPS. 3 & $\boldsymbol{\theta}$ \\
\hline ¡Evite... & ... siempre... & \multicolumn{2}{|c|}{...Señor! } \\
\hline FPS. 4 & FPS. 5 & FPS. 6 & BO \\
\hline ¡Ese mal rato! & Tomando... & \multicolumn{2}{|c|}{...bi-car-bo... } \\
\hline FPS. 7 & FPS. 8 & FPS. 9 & \\
\hline \multirow{5}{*}{$\begin{array}{c}\text { FPS. } \\
10\end{array}$} & iTorres... & \multicolumn{2}{|c|}{...Muñoz! } \\
\hline & Procedencia de la música & \multicolumn{2}{|c|}{ Extradiegética } \\
\hline & Imagen & \multicolumn{2}{|c|}{ Animada } \\
\hline & Duración & \multicolumn{2}{|c|}{ 00:00:16:19 s. } \\
\hline & Sincronía & \multicolumn{2}{|c|}{ Dura. Estilo mickeymousing } \\
\hline
\end{tabular}

Tabla 2. Bicarbonato Torres Muñoz. Análisis audiovisual.

[Fuente: elaboración propia]

Formado por una secuencia de unos dieciséis segundos, podemos observar cómo cada uno de los fotogramas analizados, que representan los movimientos y gestos de su protagonista animado, son conducidos en sincronización dura con la composición del jingle propuesto para el anuncio: "Evite siempre, señor, ese mal rato, tomando bicarbonato Torres Muñoz". Como consecuencia, el tema musical cantado de procedencia extradiegética, dado que no encontramos ningún aspecto visual que represente la fuente sonora, se convierte en parte esencial del mensaje publicitario, cuya finalización concede el protagonismo a una voz en off que describe el nombre del producto junto con una imagen real del mismo.

Lo mismo ocurrió con el anuncio cuya composición persuasiva audiovisual era muy similar; nos referimos al creado para el coñac Fundador -Tabla 3-. ${ }^{16}$ El jingle "Está como nunca", de procedencia, una vez más, extradiegética, creado para el simpático personaje que camina airosamente al comienzo del anuncio, más conocido como Don Pedrito, hace que la marca, el producto en sí mismo, perdure en nuestra memoria colectiva hasta el día de hoy. 


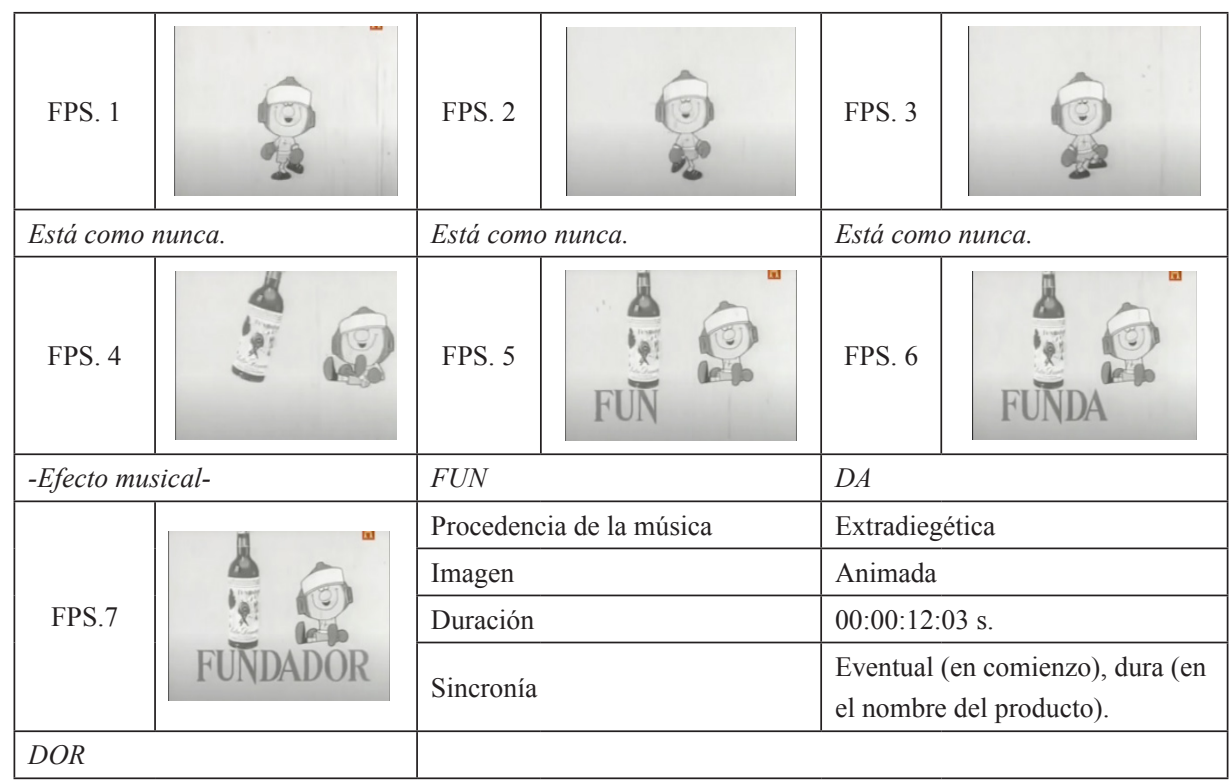

Tabla 3. Fundador. Análisis audiovisual.

[Fuente: elaboración propia]

En esta ocasión, el propio ritmo de la música es la encargada de acompañar los pasos del dibujo animado en una sincronía eventual que conducen al espectador hacia el final del spot donde, ahora sí, una vez más, de manera precisa las sílabas que componen el nombre del producto son entonadas y enlazadas con su homónimo visual. Por consiguiente, esta simplicidad audiovisual hace que la propuesta comercial del producto sea recordada con una facilidad asombrosa por el público objetivo.

Como podemos observar, existen una serie de paralelismos audiovisuales entre los dos spots publicitarios de televisión que sirvieron para el reconocimiento y consumo del producto que era promocionado. En primer lugar, ambos se desarrollan alrededor de quince segundos, un tiempo muy corto en comparación con los filmlets emitidos en la publicidad cinematográfica de la misma década y que, por lo general, constaban de una duración superior a los treinta segundos, llegando incluso al minuto de duración. ${ }^{17}$ En segundo lugar, los jingles propuestos para cada anuncio, de procedencia no diegética, son desmenuzados entre frases y palabras para acompañar, con un grado de sincronía muy preciso, algún momento concreto de la imagen animada. Por último, citados anuncios finalizan su metraje con la representación visual del protagonista animado junto al nombre y la imagen real del producto anunciado. De esta forma, nos encontramos ante unos recursos audiovisuales que permiten, en un breve espacio de tiempo, captar la atención del público mediante el uso síncrono de la imagen animada y un tema musical cantado.

17 Véase: Andalucía canta [video]. YouTube. https://www.youtube.com/watch?v=V1FTEXOE21g (Fecha de acceso: 11/07/2021) 


\section{Para concluir}

La llegada de los años sesenta y el rápido establecimiento de la televisión como la nueva herramienta para la promoción y consumo de productos supuso un punto de inflexión en la composición audiovisual para los spots publicitarios que, como citamos con anterioridad, estaban acostumbrados al formato visual y sonoro de la gran pantalla. En este sentido, el estudio de ambos anuncios propuestos como modelos para este artículo que, recordemos, fueron creados por los Estudios Moro de publicidad española en la época de los sesenta, son, de entre una enorme variedad de anuncios publicitarios que se emitieron en televisión durante este periodo, un perfecto marco para conocer, entender y analizar la composición visual y sonora de los primeros spots televisivos en España. Así, abordados desde una perspectiva audiovisual, las páginas precedentes nos llevan a concluir que los citados anuncios seguían un mismo patrón persuasivo para favorecer el recuerdo del producto en el público objetivo.

Como hemos podido observar, los dos anuncios analizados contienen una serie de parámetros audiovisuales comunes que hacen de la composición del spot publicitario un medio muy eficaz para la promoción del producto anunciado. Entre ellos, recapitulemos, está la duración del anuncio - unos quince segundos aproximadamente-, una procedencia de la música extradiegética y la combinación, en una sincronización muy precisa, del movimiento de la imagen animada junto con el ritmo y texto de un jingle que siempre finaliza entonando el nombre del producto. Asimismo, su estudio ha permitido constatar que en las secuencias analizadas siempre se advierte un último plano que contiene la imagen real del producto, acompañado, eso sí, por la animación protagonista de la marca anunciada. A su vez, es necesario incidir en el aspecto de la sincronía entre imagen y música, dado que, a través del análisis audiovisual llevado a cabo con anterioridad, se ha comprobado cómo el comportamiento conjunto de los aspectos visuales del spot con la composición musical del jingle proporciona un cóctel persuasivo muy eficaz para captar la atención del target $\mathrm{y}$, por consiguiente, facilitar el recuerdo de la marca anunciada y estampar una huella sonora que identifique el producto de forma instantánea, permaneciendo así en la memoria colectiva de los espectadores.

En suma, los anuncios planteados en este artículo son una pequeña muestra audiovisual del gran abanico artístico-publicitario que se realizó durante esta década y que, gracias a su alto poder persuasivo, han perdurado hasta la actualidad por recurrir a la combinación de una imagen animada seguida de un jingle que describe -de forma musical- las características del producto.

\section{Bibliografía}

Bassat, L. (1993). El libro rojo de la publicidad. Ideas que mueven montañas. Barcelona: Peguin Random House Grupo Editorial.

Bravo, J. (2000). "La incorporación de las multinacionales al panorama publicitario español. Now we can say: Welcome to Spain". En De Las Heras, C. (coord.), La década de oro de la publicidad en España: los años 60. Málaga, Área de Cultura, Ayuntamiento de Málaga, 118-120.

Bustamante, E. (2013). Historia de la Radio y la Televisión en España. Una asignatura pendiente de la democracia. Barcelona: Gedisa. 
Candel, J. M. (1993). Historia del dibujo animado español. España: Filmoteca Regional de Murcia.

Chion, M. (1993). La audiovisión: Introducción a un análisis conjunto de la imagen y el sonido. Barcelona: Paidós comunicación.

Chion, M. (2017). La audiovisión. Sonido e imagen en el cine. Buenos Aires: La marca editora.

Darias de las Heras, V. (2018). La música y los medios de comunicación. Madrid: Dykinson S.L.

Eguizábal, R. (1998). Historia de la publicidad. Madrid: Fragua.

Fernández, L. (2007). El anuncio de la modernidad. Estudios Moro 1955-1970. Valencia: Pentagraf Editorial.

Fundación FOESSA. (1966). I informe sociológico sobre la situación social en España. España: Cáritas Española, p.74.

Gómez Rodríguez, J. A. (2005). "Lo que no venda, cántelo. Algunas reflexiones sobre el papel de la música en la publicidad”. En Matilde Olarte (Ed.). La música en los medios audiovisuales. Algunas aportaciones. Salamanca: Plaza Universitaria Ediciones, 225266.

Guijarro, T. y Muela, C. (2003). La música, la voz, los efectos y el silencio en publicidad. La creatividad en la producción del sonido. Madrid: Dossat 2000.

Huici Módenes, A. (2017). Teoría e historia de la propaganda. Madrid: Síntesis.

Jiménez Sánchez, Á.; M. Lavín, J.; Gómez Isla, J. (2019). “Érase una vez..., la animación infantil española”. Revista Ibérica de Sistemas y Tecnologías de Información, núm. 20, 36-48.

Martín, S. (2014). “Aproximación a la historia y al papel de la televisión en la emigración española a Europa”. Migraciones y Exilios. Universidad Complutense de Madrid, núm.14, 61-84.

Montero, M. (2011). "Desarrollismo, consumismo y publicidad. Un enfoque histórico (España 1960-1975)". Pensar la publicidad. Universidad Complutense de Madrid, vol. 5, núm. 1, 249-273. https://doi.org/10.5209/rev_PEPU.2011.v5.n1.36932

Montero, M. (2014). "Los efectos perversos de la publicidad en la televisión franquista (19561975)". Estudios sobre el mensaje periodístico. Universidad Complutense de Madrid, vol. 20, núm. Especial, 139-156. https://doi.org/10.5209/rev_ESMP.2014.v20.45095

Palacio Bañuelos, L. (2020). Historia del franquismo. España 1936-1975. Córdoba: Almuzara.

Palacio, M. (2008). Historia de la televisión en España (3a. ed.). Barcelona: Gedisa.

Palacio, M. (2002). "Francisco Franco y la Televisión". Revista de Estudios Históricos sobre la Imagen (Archivos de la Filmoteca), vol. 2, núm. 42-43, 72-95.

Román, A. (2017). Análisis Musivisual. Guía de audición y estudios de la música cinematográfica. Madrid: Visión Libros.

Rueda Laffond, J. C. y Chicharro Merayo, M. del M. (2006). Televisión en España (19562006). Política, consumo y cultura televisiva. Madrid: Fragua.

Sánchez Galán, M. B. (2010). "La publicidad y la imagen en movimiento: primeros pasos del cine publicitario en España”. Pensar la publicidad. Universidad Complutense de Madrid, vol. IV, núm. 1, 79-96. (Fecha de acceso: 06/07/2021). Disponible en: https://revistas. ucm.es/index.php/PEPU/article/download/PEPU1010120079A/15126/.

Sánchez Rodríguez, V. (2015). "Música y publicidad. Una aproximación al análisis músicoaudiovisual de anuncios televisivos". Revista de Comunicación, Vivat Academia. núm. 133, 86-101. https://doi.org/10.15178/va.2015.133.86-101 
Sánchez, Á. (2011). "Los oficios de la cultura" [Archivo de video]. Recuperado de: http:// www.rtve.es/alacarta/videos/los-oficios-de-la-cultura/oficios-cultura-publicidad-tonisegarra/1230593/ (Fecha de acceso: 06/07/2021).

Sedeño, A. M. (2008). “La relación musicovisual en el videoclip. Propuestas metodológicas y tipología”. En Miguel de Aguilera, Joan E. Adell y Ana Sedeño (Eds.), Comunicación y música I: Lenguaje y medios. Barcelona: UOC, 121-140. 